\title{
Enhancement of the seismic performance of multi-storey buildings by means of dissipative glazing curtain walls
}

\author{
Chiara Bedon*, Claudio Amadio \\ University of Trieste, Department of Engineering and Architecture, Piazzale Europa 1, 34127 Trieste, Italy
}

\section{A R T I C L E I N F O}

\section{Article history:}

Received 10 July 2016

Revised 26 April 2017

Accepted 12 September 2017

\section{Keywords:}

Multi-storey building

Glazing curtain walls

Seismic events

Vibration control system

Passive structural control

Dissipative devices

Tuned-mass dampers (TMDs)

Finite-element numerical models

\begin{abstract}
A B S T R A C T
Glazing facades are widely used in building structures, due to a series of aesthetic, thermal, lightening aspects. From a structural point of view, under the action of exceptional loads as impacts, explosions or seismic events, the glazing envelopes often represent the critical component for multi-storey buildings, due to the typically brittle behavior and limited tensile resistance of the glass panes, hence requiring specific design concepts. In this paper, the feasibility and potential of special mechanical connectors interposed at the interface between a given multi-storey primary building structure and the glazing facade are extensively investigated via accurate Finite-Element models, under the action of a set of seven natural seismic records. As shown, the proposed vibration control devices can markedly improve the dynamic performance of the traditional structure, both in terms of global (i.e. building seismic response) and local performances (i.e. at the component level). The final result, once the input parameters of the vibration control devices are properly designed, is an assembled structural system in which the glazing façade works as passive control system for the primary structure.
\end{abstract}

() 2017 Elsevier Ltd. All rights reserved.

\section{Introduction and state-of-the-art}

In current practice, glazing curtain walls are extensively used in buildings, in the form of cladding envelopes able to provide specific thermal, insulation, weather resistance properties. From a structural point of view, these facades are typically designed in order to provide an appropriate resistance against lateral loads (i.e. wind), as well as to accommodate the deformations of the main structure. Due to the typically tensile brittle and limited resistance of glass, however, the cladding elements often represent a critical component for the entire building and its occupants, especially under the action of exceptional and high-rise design loads such as seismic events, explosions or impacts in general.

Despite a non-effective and expensive over-dimensioning of the glazing components, a valid technological solution for enhancing the structural performance of a given system - compared to traditional design methods - can be represented by special connectors able to reduce the effects of the incoming design loads.

In this respect, special devices have been for example proposed in [1-5], both for cable-supported facades or curtain walls under explosive events, in the form of passive control systems able to avoid the glass panes failure, as well as to preserve the integrity

\footnotetext{
* Corresponding author.

E-mail addresses: bedon@dicar.units.it, chiara.bedon@dia.units.it (C. Bedon).
}

and optimize the primary structure and hence guarantee an appropriate safety level for its occupants.

Passive control and vibration monitoring of structural systems under exceptional or high-rise design loads actually represents, both for buildings and infrastructures, a key topic for researchers and designers (i.e. [6-10]). Within the possible passive technological solutions currently available or under investigation for the mitigation of multi-storey buildings, tuned-mass-dampers (TMD) are widely used in structural engineering to reduce translational displacements and accelerations due to wind and seismic loads in bridges [11-14] and buildings or assemblies [15-19]. Den Hartog [20] first derived analytical expressions to determine the optimal values of mass, frequency and damping ratios of the TMD as a function of the dynamic properties of the structure. Several studies focused on the optimal design of such devices can be found in literature [21-24].

Regarding the dynamic performance of buildings cladded by glazing envelopes, the original TMD concept has been first extended to structural buildings with double skin façades by Moon [25-27], and also recently recalled by Palmeri et al. [28]. In these past works, it was shown through analytical studies that when special connectors are used, double skin facades can efficiently act as passive absorbers for multi-storey buildings under wind or seismic loads, with important structural benefits in terms of stress and dis- 
placement reductions (up to $\approx 35 \%$, compared to the traditional building).

In this paper, the feasibility and potential of distributed, dissipative devices able to control and mitigate the maximum vibrations and stresses due to seismic events on traditional multistorey buildings with glazing envelopes is investigated via FiniteElement (FE) numerical simulations, by taking into account a reference case study. Compared to [25-28], the current study is carried out by considering the typology of glazing curtain walls, namely composed of modular units (i.e. the insulated glass panels (IGUs) and a metal supporting frame) directly connected to the steel structure via fully rigid connectors.

The FE investigation is first carried out in ABAQUS [29], by means of accurate 3D models able to describe a full building assembly representative of a seismic resistant, 4-storey residential steel-framed building (with or without vibration control systems). Additional FE studies are also performed at the component level, in order to properly assess the effects of a given seismic load on a single IGU unit, as a part of the full building. In it, the critical aspect is in fact often represented by the maximum out-of-plane displacements achieved during the assigned seismic event, as well as by the corresponding maximum stresses.

The FE parametric study is developed by taking into account several mechanical configurations (i.e. stiffness and damping properties) for the proposed vibration control devices, so that both their effectiveness and criticalities could be properly emphasized. The exceedance of the tensile resistance of glass as well as the avoidance of excessive deformations at the devices level should be in fact avoided, for optimal design purposes. As shown, when properly designed in terms of stiffness and damping features, the investigated control devices can strongly enhance the dynamic performance of the given steel-framed system, both in terms of global dynamic performance as well as in terms of maximum deformations and stresses in the IGUs. Due to the implemented dissipative devices, the mass belonging to the glazing curtain wall is in fact efficiently involved in a kind of distributed, passive control system derived from the TMD concept. It is thus expected, based on the discussed FE study, that the current research investigation could provide useful background towards the fully development of this innovative design approach.

\section{Design concept and theoretical background}

The design concept of building structures equipped by vibration control devices and dissipative glazing curtain walls takes inspiration from the tuned-mass-damper (TMD) concept and from the implementation in traditional glazing facades of special connectors able to act as passive impact absorbers.

Recent applications of special connectors have been proposed in the last years for glazing cable supported facades under explosive events [1-4], in the form of viscous spider connectors for glass panes, as well as friction dampers or elasto-plastic restraining systems for the bracing cables, while special viscoelastic or ADAS brackets acting as passive control devices for curtain wall modular units have been proposed and extensively numerically investigated in [5]. In these past research projects, the potential of such devices for improving the dynamic performance of the cladding system was emphasized, but the overall performance of the full structural assembly consisting of the glazing façade and the cladded building was not properly explored.

The use of passive vibration control systems for the enhancement of the dynamic performance of tall buildings under wind pressures and seismic events was first explored in [25-27], where a theoretical study was carried out on building structures with double skin facades, in order to find an optimal correlation between the primary structure, the (double skin) glazing façade and the devices' mechanical properties. The same concept has been recently analytically investigated also in [28], where it was further highlighted that double skin facades with appropriate vibration control connectors can provide marked contribution in the reduction of the effect due to seismic events on tall buildings, with a reduction of the expected maximum displacements up to $35 \%$ the deformations of the traditional building structures.

In this research project, the design concept of glazing curtain walls acting as passive absorbers for building structures under seismic events is further extensively investigated via computationally efficient but accurate FE models, both in terms of global dynamic performance and structural effects of a given design seismic load, as well as at a component level (i.e. maximum stresses and deformations in the glazing modular units).

In accordance with [25-28], the dynamic performance of a building structure with glazing facades and vibration control devices can be rationally described as schematized in Fig. 1.

The primary structure, having total mass $M_{\text {struct }}$, with specific stiffness $\left(K_{\text {struct }}\right)$ and damping $\left(c_{\text {struct }}\right)$ properties, interacts with the cladding glazing façade - namely representative of an additional mass $\left(M_{\text {glass,tot }}\right)$ on the primary structure - via special mechanical connectors replacing the typically fully rigid supports.

From a theoretical point of view, see Fig. 2, the dynamic response of the system of Fig. 1 can be in fact rationally associated to a single-degree-of-freedom (SDOF) system interacting with the additional mass representative of the full glazing envelope, via a series of distributed vibration control devices, whose mechanical performance can be described in terms of elastic stiffness $K_{d, t o t}$ and damping coefficient $c_{d, t o t}$

Under a given design load, see Fig. 2, the governing differential equations representative of the dynamic performance of the SDOFTMD system are [26]:

$$
\begin{aligned}
& M_{\text {struct }} \ddot{u}(t)+C_{\text {struct }} \dot{u}(t)+K_{\text {struct }} u(t) \\
& \quad=P(t)+C_{d, t o t} \dot{u}_{d}(t)+K_{d, \text { tot }} u_{d}(t) \\
& M_{\text {glass, tot }} \ddot{u}_{d}(t)+C_{d, \text { tot }}\left(\dot{u}_{d}(t)-\dot{u}(t)\right)+K_{d, \text { tot }}\left(u_{d}(t)-u(t)\right)=p(t)
\end{aligned}
$$

where $u(t)$ is the deflection in time of the primary structure, while $u_{d}(t)$ denotes the relative displacement of the glazing curtain wall depending on the stiffness $K_{d, t o t}$ and damping ratio $c_{d, t o t}$ of the devices. $P(t)$ and $p(t)$, being representative of the force acting on the main mass or on the TMD mass respectively, for the case of seismic loading condition are given by:

$$
\begin{aligned}
& P(t)=-M_{\text {struct }} \ddot{u}_{g}(t) \\
& p(t)=\frac{M_{\text {glass,tot }}}{M_{\text {struct }}} P(t)
\end{aligned}
$$

with $\ddot{u}_{g}(t)$ the exciting base acceleration.

In this study, assuming that the single glazing component is connected to the adjacent steel frame with four special dissipative devices (i.e. one device at each panel corner), the preliminary estimation of the devices' stiffness and damping properties can be carried out based on Fig. 3.

In accordance with Fig. 3, $M_{\text {glass }}$ represents in fact the total mass of a single façade panel (plus the supporting aluminum frame), while $K_{d}$ and $c_{d}$ denote respectively the stiffness/damping ratio of a single device, with $K_{d, \text { glass }}=4 K_{d}$ and $c_{d, \text { glass }}=4 c_{d}$ denote the resulting values at the level of glazing modular unit.

From a practical point of view, the typical device can be supposed a viscoelastic (VE) solid damper composed of three metallic plates and a middle layer, namely a natural rubber. The VE layer is has nominal thickness $h_{d}$ and a square base surface $A_{d}=l_{d}^{2}$ (see Fig. $3 \mathrm{~b}$ and $\mathrm{c}$ ). Two steel plates are directly attached to the struc- 


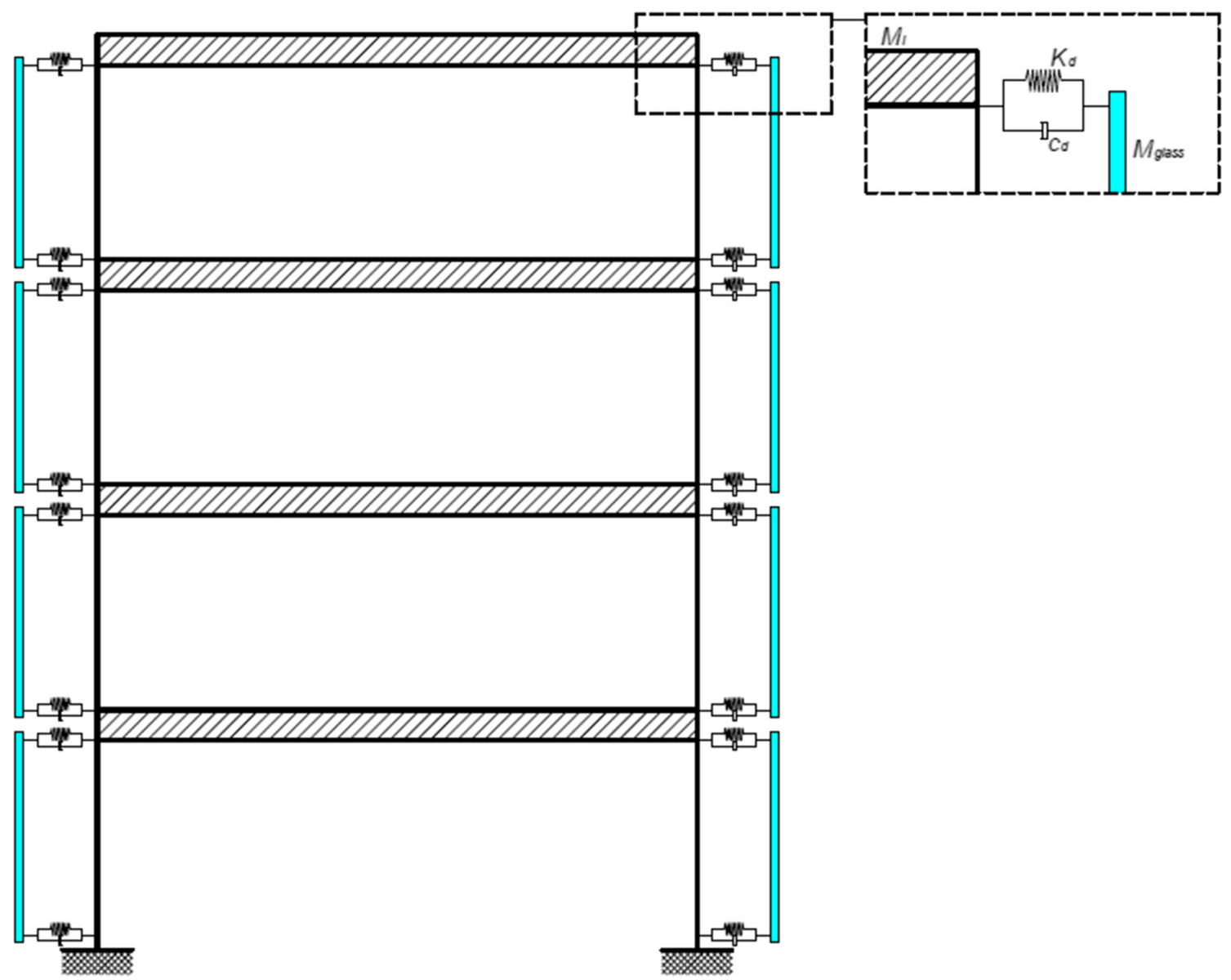

Fig. 1. Simplified mechanical model for the analysis of a building structure with dissipative glazing curtain wall (lateral view).

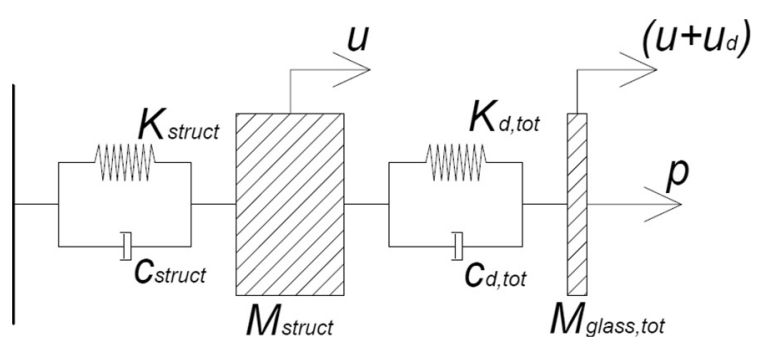

Fig. 2. Reference mechanical model for the analysis of a SDOF system with TMD.

tural backup (e.g. the reinforced concrete slab) by means of anchoring bolts, whereas the third steel plate (e.g. the sliding bracket) supports the tubular frame of the curtain wall, enabling possible crushing of the rubber layer and rotations. In this manner, due to an assigned pressure on the glass surface, it is expected that the full device would slide in the same direction.

The prototype of Fig. 3 takes inspiration from classical viscous dampers investigated since decades for the seismic mitigation of tall buildings, see for example [30-33]. In [30], based on experimental studies, it was shown that the static and dynamic response of such dampers is characterized by a rather stable linear viscous behaviour, with limited effects of temperature variations. The same experiments also emphasized the high dissipative potential of solid VE dampers, when subjected to vibrations leading up to $200 \%$ shear strains as well as for limited amplitude of vibrations, in the range of few $\mu \mathrm{m}$. For design purposes, given the linear viscoelastic behaviour of VE solid dampers, the key parameters for the proposed devices under well-defined loading conditions (e.g. damper operating frequency $\omega$ and temperature $T$ ) are the damping ratio $c_{d}$ deriving from the rubber compound and the corresponding elastic stiffness $K_{d}$, where [33]:

$c_{d}=c_{d}(\omega)=\frac{K^{\prime \prime}}{\omega}=\eta \frac{K^{\prime}}{\omega}$,

with $\eta$ the loss factor of the VE compound and

$K^{\prime}=\frac{G^{\prime}(\omega) A_{d}}{h_{d}}$

$K^{\prime \prime}=\frac{G^{\prime \prime}(\omega) A_{d}}{h_{d}}$

the storage and loss stiffnesses respectively, where $G^{\prime}(\omega)$ and $G^{\prime \prime}(\omega)$ denote the corresponding shear moduli.

Given the fundamental period of vibration $T_{1}$ of the primary structure (to be properly estimated, see Section 4), the optimal design of the vibration control devices' stiffness $K_{d}$ could be preliminary carried out by equaling $T_{1}$ and the fundamental period $T_{1}$ ,glass of the modular unit of Fig. 3a. As far as the total mass $M_{\text {glass }}$ of the unit is known, the stiffness $K_{d}$ of a single connector can in fact be calculated as:

$K_{d}=\frac{1}{4} K_{d, \text { glass }}=\frac{1}{4} \frac{M_{\text {glass }}}{\left(\frac{T_{1, \text { glass }}}{2 \pi}\right)^{2}}=\frac{M_{\text {glass }} \pi^{2}}{T_{1, \text { glass }}^{2}}$

by assuming $T_{1, \text { glass }}=T_{1}$. 


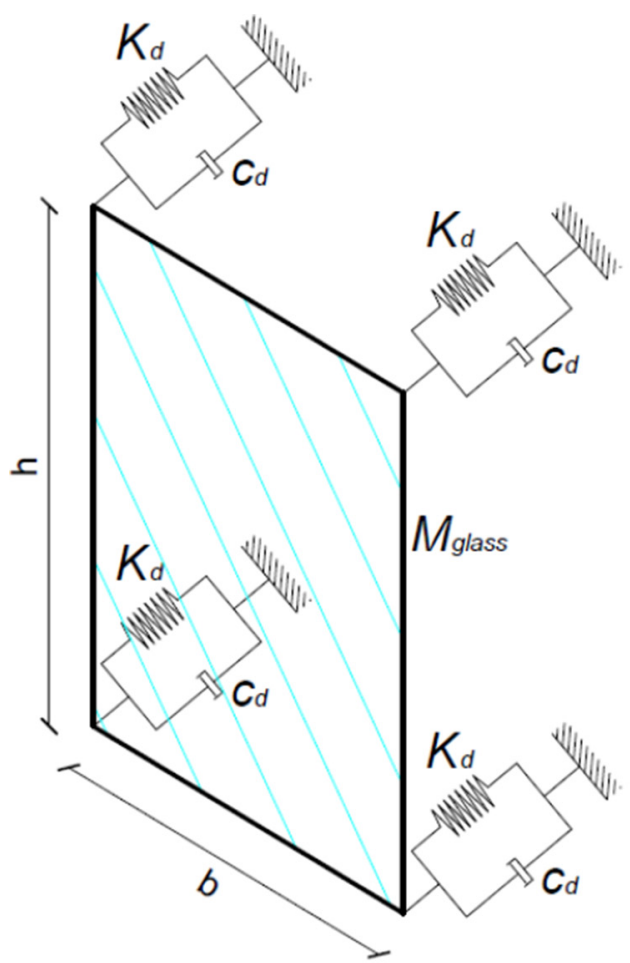

(a)

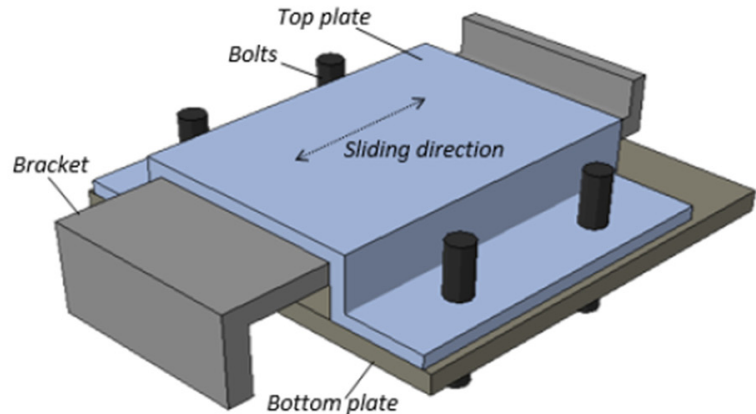

(b)

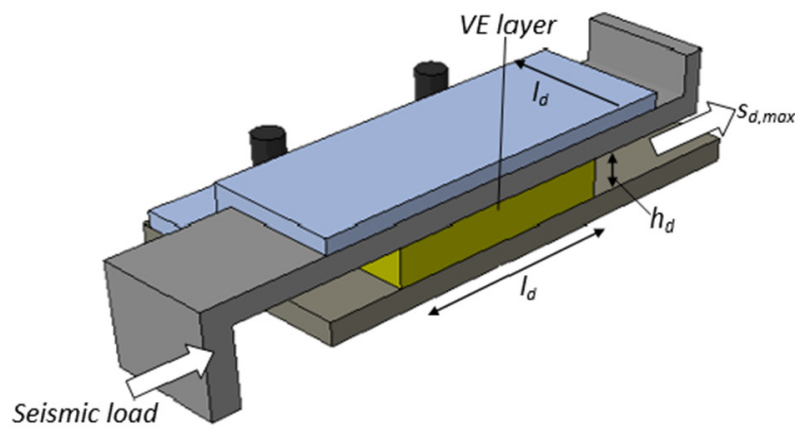

(c)

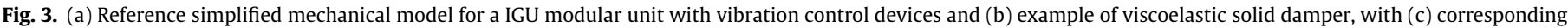
transversal cross-section. by:

The corresponding damping term, based on Eq. (7), is then given

$c_{d}=\frac{1}{4} c_{d, g l a s s}$,

where [35]:

$c_{d, \text { glass }}=\xi \cdot c_{c r}=\xi \cdot 2 M_{\text {glass }} \omega_{1, \text { glass }}$,

$\omega_{1, \text { glass }}$ is the operating frequency of the glazing modular unit assumed to coincide with the damper operating frequency, $\xi$ the damping coefficient of the dissipative device and $c_{c r}$ its critical value.

Considering the vibration control system consists of a rubber layer with $\xi$ the material damping, $c_{d}$ can be directly calculated based on Eq. (8). The corresponding stiffness $K_{d}$ can then be related to the device nominal dimensions, in accordance with Eq. (5) and Fig. $3 \mathrm{~b}$, while under a given design load possible failure mechanisms in the rubber (i.e. tearing) should be properly prevented by limiting its maximum shear strains $\gamma$ or deformations $s_{d, \max }$ (see also $[2,5])$ :

$s_{d, \text { max }} \leqslant \min \left(2 h_{d} ; 30\right), \quad$ in $[\mathrm{mm}]$.

For design purposes, based on Eqs. (3)-(8), it is clear that as far as a certain flexibility $K_{d}$ is assigned to the adopted control devices, a marked reduction of the maximum effects on the main structural components is expected, despite very large deformations $s_{d, \max }$ at the level of the devices themselves as well as in the IGU components. A high value of connector stiffness $K_{d}$, conversely, would result in higher damping capacities $\left(c_{d}\right)$ for the devices, and hence in a strong mitigation of the incoming design loads, but could fully vanish the benefits of an additional flexibility $K_{d}$ at the level of the façade-to-steelwork connection.
A calibration procedure should be consequently carried out, so to maximize the possible benefits of the proposed design concept.

\section{Reference case study}

The reference case study consists of a 4-storey, continuous steel frame building located in an earthquake-prone region of Italy. The building, assumed to have a residential destination (category of use "A", in accordance with the Eurocode 1 provisions [36]), has $10 \mathrm{~m} \times 20 \mathrm{~m}$ base dimensions, with $12 \mathrm{~m}$ the total height, 3 and 2 bays in the longitudinal and transversal directions respectively (see Fig. 4). Inter-storey floors are supposed composed of steelconcrete composite slabs, hence providing in-plane rigid diaphragms to the building. As external envelope, a glazing curtain wall composed of IGU modular units directly connected to the perimeter steelwork is considered (see the detail of Fig. 4 and Fig. 5).

The design of all the steel members, S275 grade with $f_{y}=275$ MPa and $f_{u}=360 \mathrm{MPa}$ the yielding and collapse stresses respectively, was carried out in accordance with the recommendations of the Eurocode 3 [37], by taking into account the effect of permanent loads and accidental loads under ultimate (ULS) and service (SLS) limit state conditions. The appropriate resistance of the continuous frame to lateral loads, as well as the avoidance of possible buckling phenomena in the beams and columns, was also ensured, by providing adequate rigidity to the steel members.

In doing so, the design dead load of floor materials, resulting in $4.3 \mathrm{kN} / \mathrm{m}^{2}$, was calculated by taking into account a typical steelconcrete floor system (i.e. concrete slab, insulation, steel deck, etc.). The additional dead load deriving from the glazing envelope was also taken into account. A superimposed design live load of $2.0 \mathrm{kN} / \mathrm{m}^{2}$ was finally introduced in order to consider, as pre- 


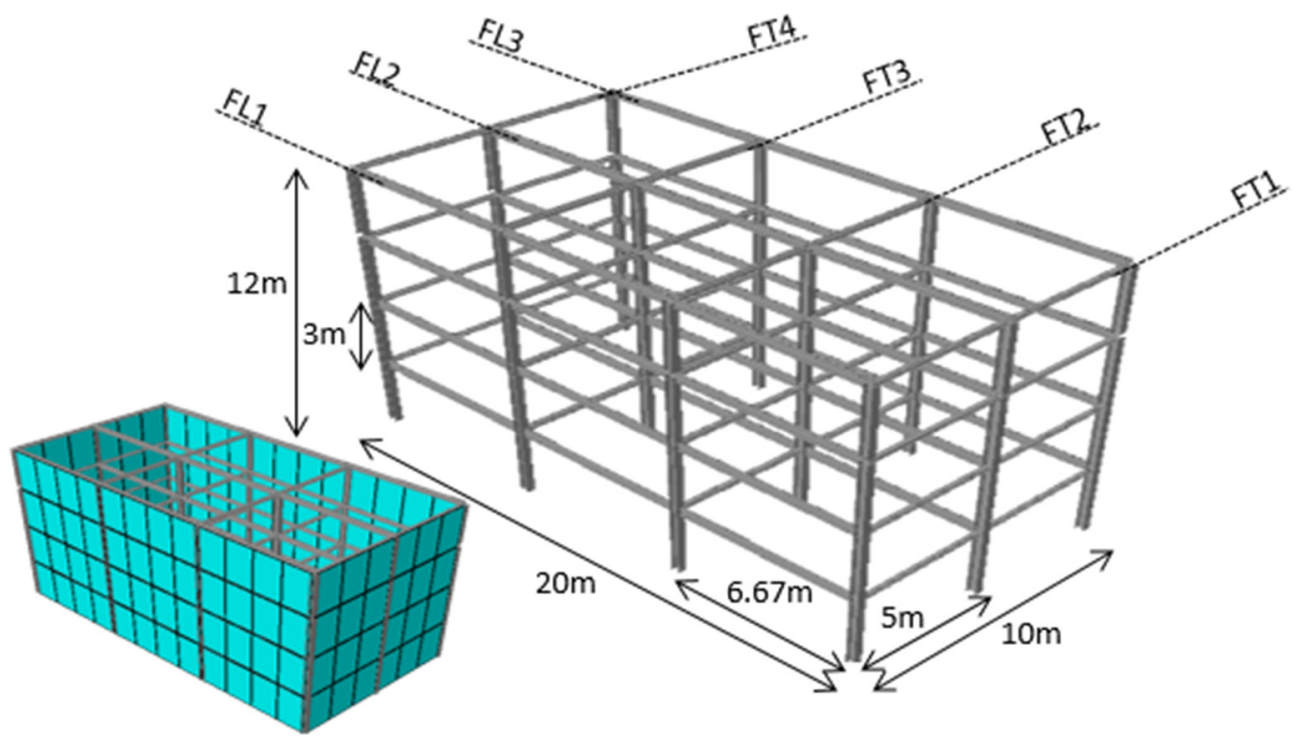

Fig. 4. Reference building structure.

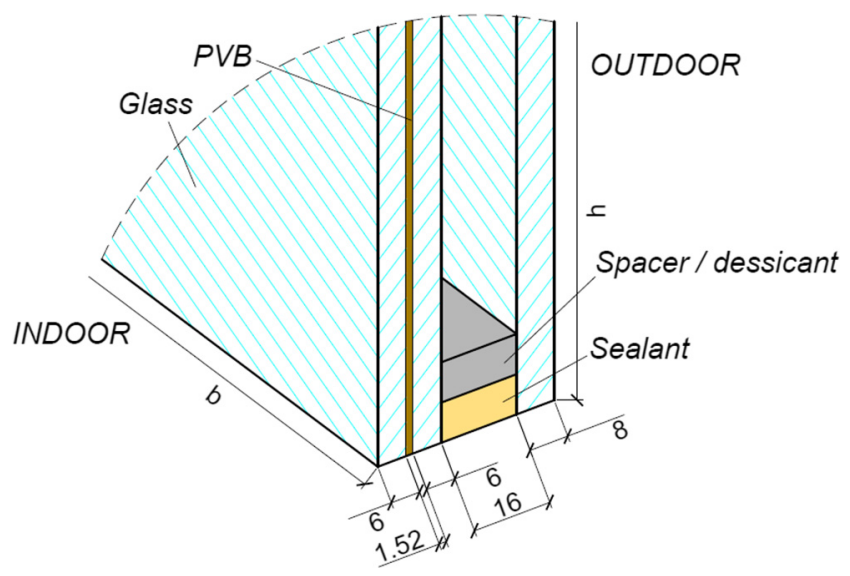

Fig. 5. Glazing curtain wall. Example of a typical IGU modular unit (cross-sectional detail, with nominal dimensions in millimeters).

scribed by [36], the additional live loads on floors belonging to residential buildings.

Fully rigid beam to column connections were considered, and assumed to appropriately transfer the beam ends moments and shear forces into the adjacent columns. The resisting section of the adopted columns and beams (see Table 1), in this study, was defined by taking into account a High Ductility Class for the structure.The condition:

$\sum M_{c, p l, R d} \geqslant \gamma_{R d} \sum M_{b, p l, R d}$

was hence preliminary verified, with $M_{c, p l, R d}$ and $M_{b, p l, R d}$ the design resistant plastic moment of each column and beam respectively, while $\gamma_{R d}=1.3$. A key role was assigned, when designing the steel frame, to the satisfaction of the condition given in Eq. (11), so that

Table 1

Member sections for the 4-storey seismic resistant steel building.

\begin{tabular}{llll}
\hline & \multicolumn{2}{l}{ Storey \#1-4 } & \\
\cline { 2 - 4 } Bay & Columns & Primary beams & Secondary beams \\
\hline Internal & HEB 340 & IPE 360 & IPE 270 \\
External & HEB300 & IPE 330 & IPE 240 \\
\hline
\end{tabular}

the occurrence of plastic hinges during the assigned seismic events could occur at the beam ends rather than in the columns, hence guaranteeing a ductile damage mechanism for the full steel frame.

Regarding the building enclosure, the glazing curtain wall was then supposed composed of modular IGUs spanning from floorto-floor, continuously supported by means of an aluminum frame and rigidly connected to the main structure by means of fully rigid steel brackets.

In accordance with Fig. 3a, a total dimension of $h=2.90 \mathrm{~m} \times b=1.6 \mathrm{~m}$ was considered for each façade modular unit. The glass sheets of the IGU assembly consisted then of a monolithic, $8 \mathrm{~mm}$ in thickness annealed glass ply (outdoor side), plus a laminated glass panel obtained by assembling two $6 \mathrm{~mm}$ thick heat strengthened glass plies with $1.52 \mathrm{~mm}$ thick PVB foil (indoor). The spacer between the external and the inner glass layers, finally, was supposed to be $16 \mathrm{~mm}$ thick, see Fig. 5 .

\section{Finite-element assessment of the overall effects of dissipative-glazing curtain walls}

Finite-Element simulations were carried out in ABAQUS, so that the feasibility and potential of the proposed design concept could be quantified, based on the seismic performance of the reference building with dully rigid brackets.

\subsection{FE modelling of the reference MO building}

The "M0" model, representative of the reference model with fully rigid connectors at the interface between the building and the glazing façade, was first implemented (Fig. 6).

The FE model of the case study building consisted in beam elements (B31 type) for the full steel framed structure, with I-shaped beam profiles able to reproduce the nominal geometry of the designed beams and columns, in accordance with Table 1.

At the same time, 2D shell elements (S4R type) were used to describe the glazing curtain wall plies. In this latter case, the nominal IGU cross-section of Fig. 5 was schematically described by taking into account a monolithic shell section composed of glass only and having an equivalent total thickness $t^{*}=20 \mathrm{~mm}$. This latter value was derived from the nominal glass thicknesses provided in Fig. 5, in order to take into account - although in a simplified way - the actual total mass $M_{\text {glass }} \approx 230 \mathrm{~kg}$ of the IGU panel for 


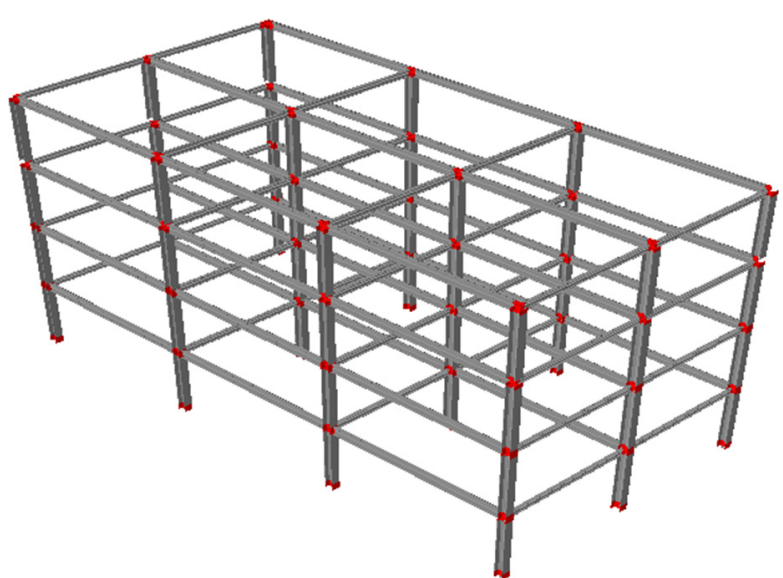

Fig. 6. Steel frame assembly, with evidence of the rigid links (in red) for the description of beam-to-column joints (ABAQUS).

the assessment of the global seismic performance of the investigated building.

In a subsequent stage of analysis only (see Section 5), the structural performance of the IGU panels themselves was also properly analysed, at a component level, via detailed FE models able to accurately reproduce the nominal geometry of a single modular unit including the gas cavity - hence to correctly estimate both the expected maximum deformations and stresses in the glass elements.

In terms of materials characterization, a Von Mises elastoplastic constitutive law was used for all the steel members, with $E_{s}=210 \mathrm{GPa}$ the Young's modulus, $v_{s}=0.3$ the Poisson's ratio and $\rho_{s}=7800 \mathrm{~kg} / \mathrm{m}^{3}$ the density. The nominal yielding and collapse stresses were taken into account [37].

Regarding the steel joints only, in order to mechanically reproduce the presence of a rigid link at the connection between the beam ends and the adjacent columns, an idealized, fully rigid material with indefinitely linear elastic constitutive behavior was used. A joint length equal to the beam height was considered, for all the so modelled rigid links (see Fig. 6).

In accordance with [34], a structural damping equal to $\xi_{s}=2 \%$ was then taken into account for all the steel components, as recommended for steel frames with welded joints. This structural damping term was numerically described, in the form of material characterization, as a Rayleigh mass-proportional damping contribution [35]:

$\alpha=2 \xi_{s} \omega_{1, M 0}=2 \xi_{s} \frac{2 \pi}{T_{1, M 0}}=0.571$,

with $T_{1, M 0}=0.326 \mathrm{~s}$ the fundamental vibration period of the reference building, as numerically calculated (see Section 4.3.1). Although neglecting possible stiffness-proportional damping effects, the assumption of Eq. (12) was considered well representative of the expected dissipation from the examined steel frame, being the mass-proportional damping especially accurate for buildings and systems in which the fundamental vibration periods are dominant, compared to higher modes (see for example $[35,36]$ ).

At the façade level, conversely, any kind of damping contribution due to glass and PVB was fully neglected.

In this latter case, the major damping contribution was in fact expected to derive from the proposed dissipative connectors.

In terms of mechanical characterization of glass, a linear elastic mechanical law was considered, with $E_{g}=70 \mathrm{GPa}$ the nominal Young's modulus, $v_{g}=0.23$ the Poisson's ratio and $\rho_{g}=2490 \mathrm{Kg}$ the density, hence fully disregarding the possible tensile failure of the glass panels during the assigned seismic events [37]. The refined analysis in terms of stress/strain effects of the same seismic events on the single glass sheets was in fact carried out on separate FE models, at a component level only, see Section 5 .

A key role was then assigned in the MO model to a set of mechanical interactions and constraints, properly implemented in order to take into account the desired restraint conditions and interactions among the building components (i.e. IGU panel to steel frame interaction, inter-storey floors, etc.).

"Coupling" kinematic constraints were introduced at the level of each inter-storey floor, so that the effects of in-plane fully rigid diaphragms could be properly taken into account. A reference node representative of the centre of gravity of each storey was defined and used as master node for the corresponding coupling constraints. A set of lumped masses representative of the seismic weights of each storey were also assigned to the same master nodes, see Section 4.3.

The mechanical interaction between each IGU panel and the adjacent steel frame was then defined in the form of assembled connectors, attached at the panels' corners and at the corresponding mesh node of the frame (see the schematic representation of Fig. 3a). The mechanical behavior of these connectors was defined so that - for the M0 building model only - a rigid restraint could be guaranteed in the direction perpendicular to the glass surface (i.e. fully rigid brackets). Possible relative rotations in the plane of the IGU panels were also properly prevented, while in-plane relative displacements (with the exception of one panel corner only) were not restrained. Along the vertical edges of each glass panel, finally, a rigid "tie" constraint able to avoid relative displacements between them was used, so that for two adjacent glass panels, the same out-of-plane deformations could be guaranteed (i.e. structural continuity of the curtain wall).

\subsection{FE modelling of the building with vibration control devices}

In order to properly explore the feasibility and potential of vibration control devices, various FE models characterized by specific mechanical configurations for the dissipative connectors were directly derived from the MO building, by replacing the fully rigid glass-to-frame brackets with of appropriate joints.

Cylindrical mechanical connectors allowing for relative displacements of glass restrained nodes in the direction orthogonal to the façade, with respect to the supporting steel frame, were used. In terms of mechanical characterization of such connectors, a linear constitutive law was taken into account, based on the assigned $K_{d}$ elastic stiffness. The corresponding damping term was also assigned, in accordance with input parameters collected in Table 2.

The reproduced effect of the so implemented joints, once optimally designed in terms of axial stiffness and damping properties, was comparable to Fig. 3a. Table 2 summarizes the main mechanical properties of some selected FE models, whose devices' stiffness and damping properties were calculated in accordance with Eqs. (6) and (8), respectively. In doing so, at the current stage of the research project, a high damping rubber was taken into account for the parametric FE study $\left(\xi=20 \%\right.$ and $G^{\prime}=0.35 \mathrm{MPa}$ $[38,39,41,42])$.

In Table 2, some selected FE results are proposed, as obtained from extended investigations, as a function of a non-dimensional magnifying coefficient $R_{K}$. Following Eq. (6), $R_{K}$ was defined so that the actual stiffness of a single device could be calculated as (with $\left.0 \leq R_{K} \leq \infty\right)$ :

$K_{d}=\left(\frac{M_{\text {glass }} \pi^{2}}{T_{1, M 0}^{2}}\right) \cdot R_{K}$ 
Table 2

Mechanical properties of the vibration control devices, in accordance with Eqs. (6) and (8).

\begin{tabular}{|c|c|c|c|c|c|c|c|}
\hline & Model \# & $\begin{array}{l}K_{d} \\
{[\mathrm{kN} / \mathrm{m}]} \\
(\mathrm{Eq} .(6))\end{array}$ & $\begin{array}{l}c_{d} \\
{[\mathrm{~kg} \mathrm{~s}]} \\
(\mathrm{Eq} .(8))\end{array}$ & $\begin{array}{l}R_{K} \\
\text { (Eq. (13)) }\end{array}$ & $\begin{array}{l}h_{d} \\
{[\mathrm{~mm}]}\end{array}$ & $\begin{array}{l}l_{d} \\
{[\mathrm{~mm}]}\end{array}$ & $\begin{array}{l}s_{d, \max } \\
{[\mathrm{mm}]} \\
\text { Eq. }(10)\end{array}$ \\
\hline Fully rigid bracket & M0 & $\infty$ & 0 & - & - & - & - \\
\hline \multirow[t]{7}{*}{ Vibration control device } & MK1 & 22.80 & 710.28 & 1 & 245 & 40 & 30 \\
\hline & MK2 & 45.61 & 1004.48 & 2 & 19 & 50 & 30 \\
\hline & MK3 & 68.41 & 1230.24 & 3 & 12.5 & 50 & 25 \\
\hline & MK4 & 91.22 & 1420.56 & 4 & 9.5 & 50 & 19 \\
\hline & MK5 & 114.02 & 1588.23 & 5 & 8 & 50 & 16 \\
\hline & MK10 & 228.04 & 2246.10 & 10 & 5.5 & 60 & 11 \\
\hline & MK50 & 1140.21 & 5022.42 & 50 & 3 & 100 & 6 \\
\hline
\end{tabular}

As such, $R_{K}=1$ is representative of the reference 'M0' system. When $R_{K} \rightarrow \infty$ the devices are expected to behave as fully rigid brackets $\left(K_{d} \rightarrow \infty\right)$, hence the damping potential given by Eq. (8) vanishes. For $R_{K} \rightarrow 0$, conversely, limited damping benefits are expected, with marked flexibility a relative displacements of the glazing system.

Based on Eq. (13), various configurations were taken into account for the design of the proposed devices. For each of the explored configurations, once the value of $R_{K}$ was set, a reliable geometry was also defined. Some tentative nominal dimensions for the rubber layer are in fact also proposed in Table 2, where $h_{d}$ is the layer thickness according to Fig. 3 , while $l_{d}$ the base dimension, assuming a square shape for each device.

\subsection{Eigenvalue and seismic analyses of the full $3 D$ building structure}

The exploratory FE study on the reference M0 building and the MKn FE models with vibration control devices was carried out both in the form of eigenvalue modal simulations (see Section 4.3.1) and nonlinear dynamic seismic analyses (Section 4.3.2), so that the efficiency and possible criticalities of the investigated design concept could be properly explored.

In both the cases, at a preliminary step, the permanent vertical loads were assigned to all the steel beams in the form of uniform line loads, depending on the respective area of influence. The dead loads due to the self-weight of the steel members and glass panels were automatically distributed on each full FE model, in the form of gravity loads. The seismic weights due to loads were separately computed at the level of each floor, and assigned to the reference master node of each inter-storey in the form of lumped masses.

All the eigenvalue and nonlinear dynamic seismic simulations, as a result, were carried out on pre-loaded building models under the effects of vertical loads in seismic conditions. In a subsequent phase only, see Section 5, additional FE models representative of a single IGU modular unit were also properly investigated.

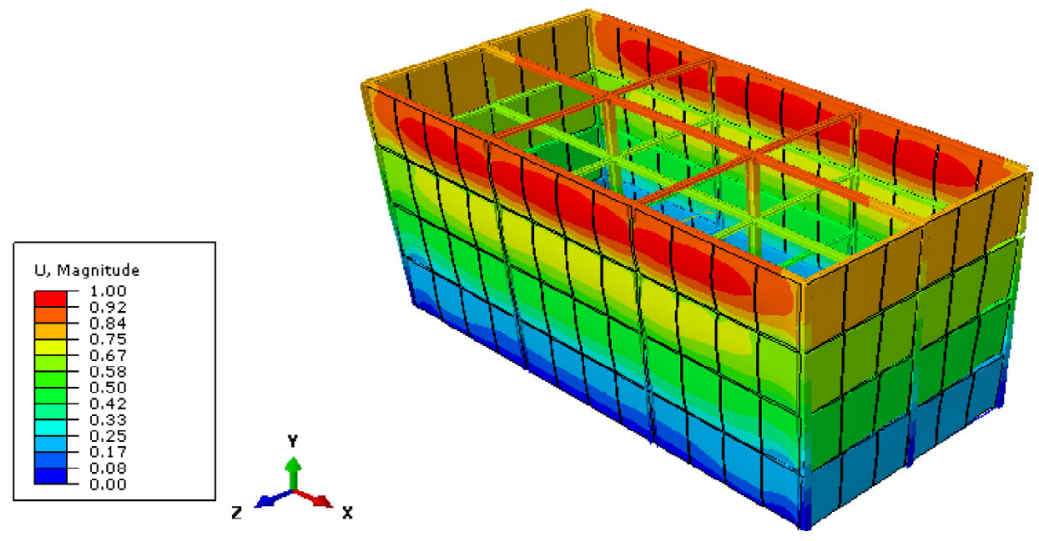

(a) Mode $1, T_{1, \mathrm{M} 0}=0.326 \mathrm{~s}$

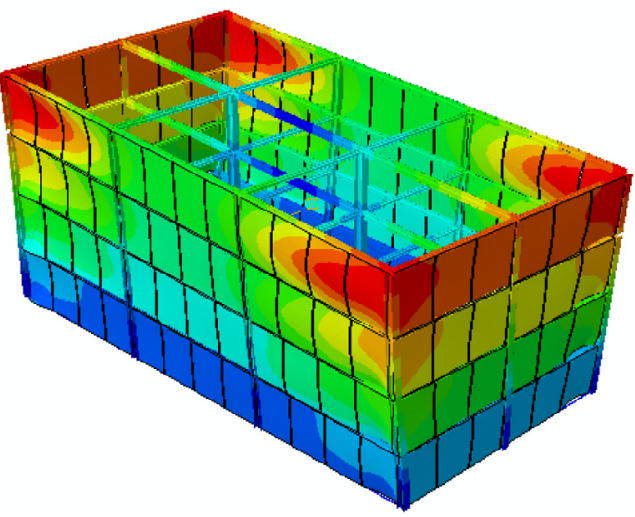

(b) Mode 2, $T_{2, M 0}=0.259 \mathrm{~s}$

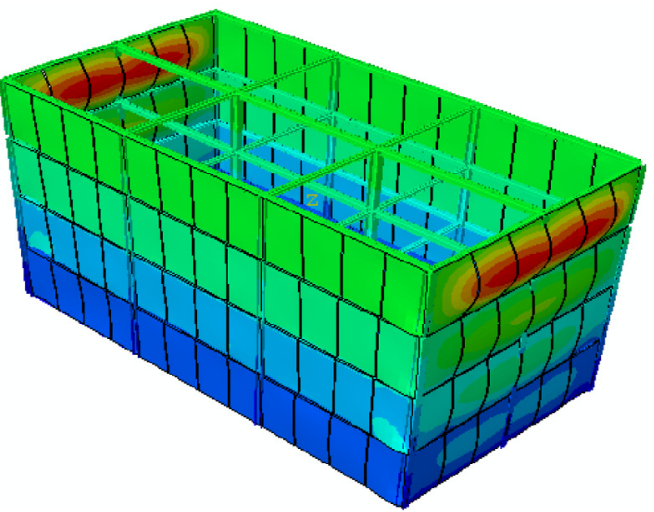

(c) Mode 3, $T_{3, M 0}=0.191 \mathrm{~s}$

Fig. 7. Fundamental vibration modes and frequencies of the M0 model. Eigenvectors normalized by mass (ABAQUS). 


\subsubsection{Vibration modes and periods}

For the M0 model, as well as for all the selected MKn configurations, the three first vibration modes were numerically predicted in ABAQUS. A qualitative comparison of dynamic effects due to the additional flexibility deriving from the devices themselves was thus carried out - compared to the reference M0 model results in the form of vibration shapes and periods. Figs. 7 and 8 present the so obtained vibration modes for the M0 model, in terms of full 3D assembly or with evidence of the steel frame only, respectively.

The first vibration mode was found to be translational along the transversal $(z)$ direction, with $T_{1, M 0}=0.326 \mathrm{~s}$ the corresponding period. In terms of effects of the dissipative connectors on the vibration properties of the M0 building, no tangible effects were found for the vibration shapes of Figs. 7 and 8 for most of the examined configurations. Global vibration modes according with Figs. 7 and 8 were in fact detected as fundamental modes for the $M K_{n}$ models, see an example in Fig. 9(a). A coefficient $R_{K} \geq 50$ in Eq. (13) proved to coincide - for the examined case study - with almost fully rigid connectors, hence suggesting limited benefits due to devices themselves. $R_{K}$ values lower than 2, conversely, gave evidence of qualitatively high relative deformations of the glazing façade, compared to the steel frame. In this respect, critical observation of FE predicted modes also emphasized the occurrence of additional local vibration modes for the glass panes. These modes, however, proved to not affect the fundamental vibration modes of the fully assembled structural system, being associated to typically higher vibration frequencies.
Beside the similarity of achieved fundamental FE shapes (see Figs. 7-9(a)), interesting variations were also observed in terms of vibration periods for the examined configurations.

As far as the devices stiffness $K_{d}$ was decreased from the M0 reference case (i.e. $K_{d} \rightarrow \infty$ ) via the $R_{K}$ multiplier in accordance with Table 2 , in fact, the corresponding periods of vibration of the building typically increased, see Fig. 9(b). An overall nonlinear dependency was found between the period variations and the added flexibility due to passive devices. A strong limit of the eigenvalue results compared in Fig. 9 is given, however, by the total lack of any information related to the effects deriving from the additional damping provided by the dissipative devices. The structural performance of the 3D FE models with vibration control systems was thus properly extended by means of nonlinear dynamic seismic analyses.

\subsubsection{Seismic performance}

In order to assess the global structural performance under earthquake events, the effects of a set of seven natural seismic accelerograms obtained from REXEL v.3.5 software [43] were taken into account for each one of the 3D FE models collected in Table 2. All the earthquake records, consisting of two-component acceleration data, were derived to be consistent with the Eurocode 8 [34] displacement spectrum having properties associated to a Peak Ground Acceleration of $0.35 \mathrm{~g}$, with type A soil (rock soil), topographic category $\mathrm{T} 1$ and nominal life of 50 years (Ultimate Limit State). A maximum lower and upper tolerance of $10 \%$ was considered in their derivation (see Fig. 10).

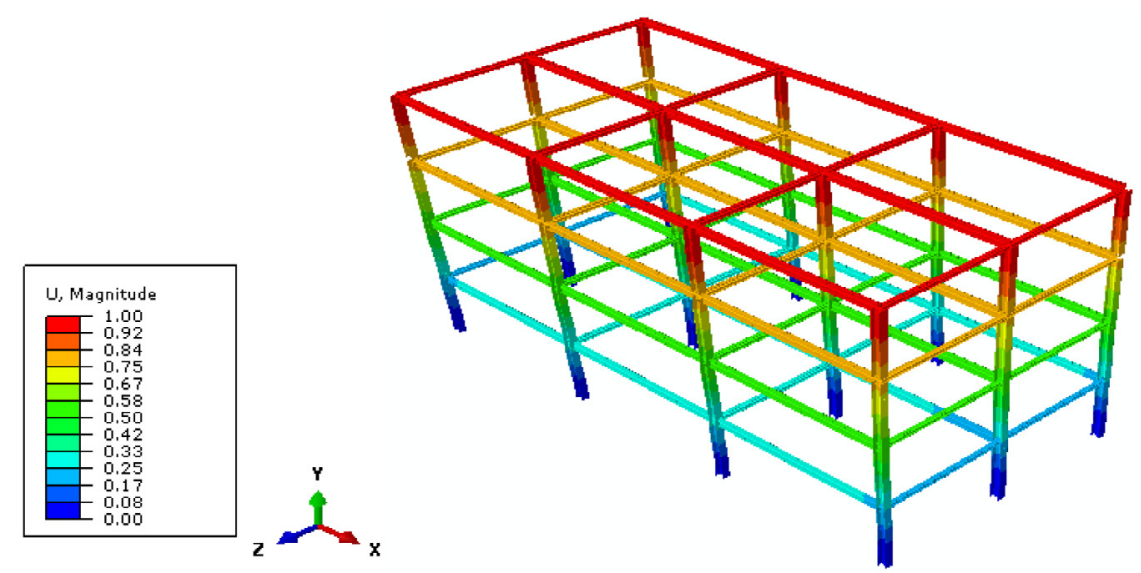

(a) Mode $1, T_{1, M 0}=0.326 \mathrm{~s}$

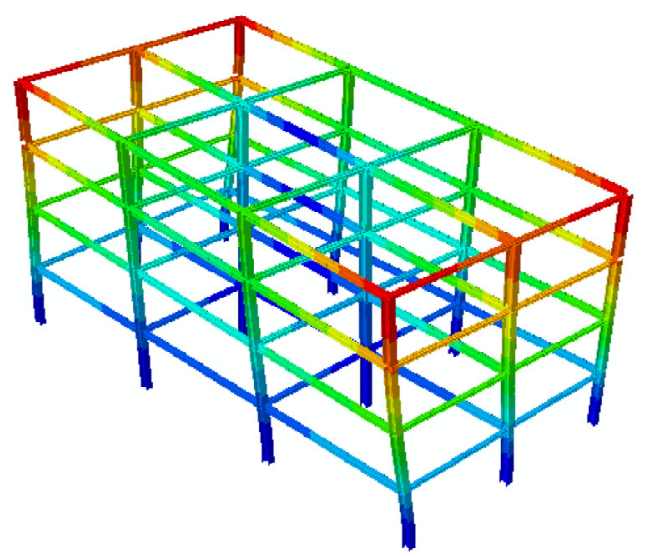

(b) Mode 2, $T_{2, M 0}=0.259 \mathrm{~s}$

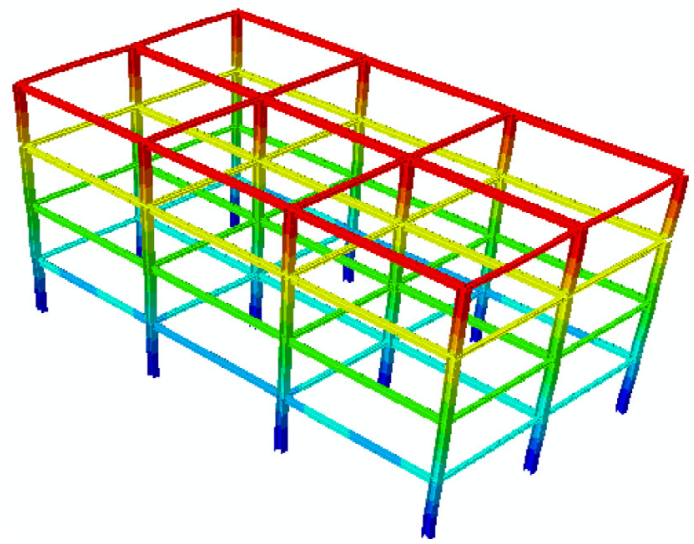

(c) Mode 3, $T_{3, M 0}=0.191 \mathrm{~s}$

Fig. 8. Fundamental vibration modes and frequencies of the MO model. In evidence, the steel frame only. Eigenvectors normalized by mass (ABAQUS). 


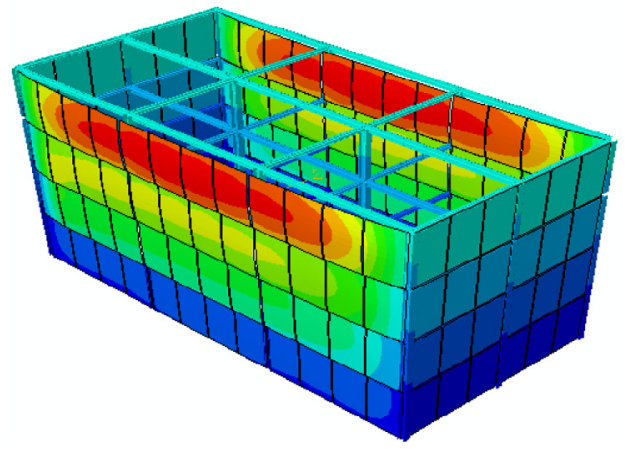

MK1

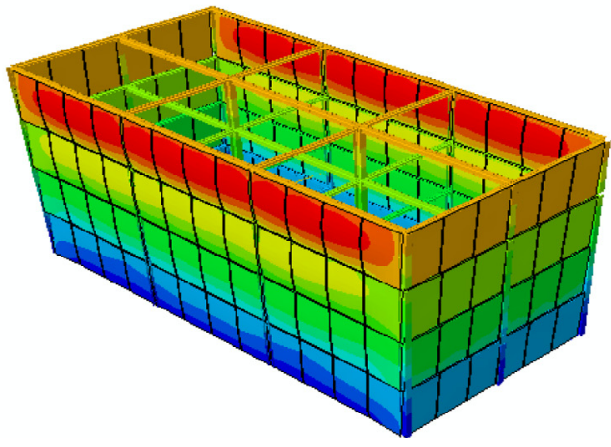

MK10

(a)

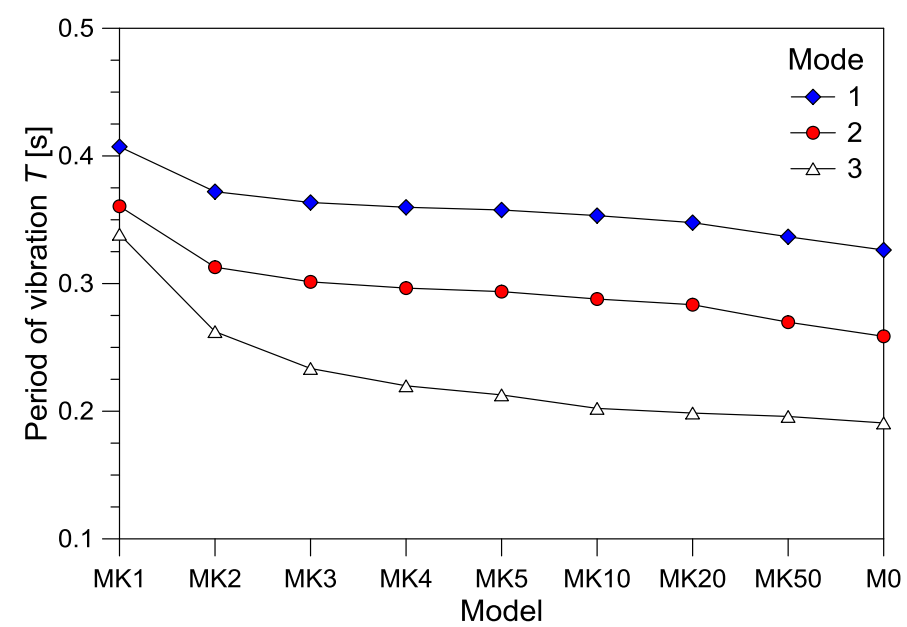

(b)

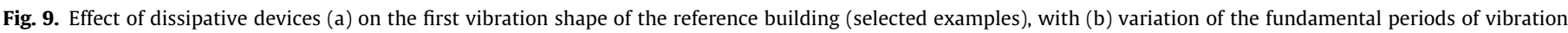
(ABAQUS).

For clarity of presentation, the seismic spectra listed in Fig.10b were then labelled as "seismic record $\# 1, \ldots$.., \#7, by taking into account the same legend order. Through each seismic simulation ( 7 for each FE model), the so calculated acceleration records were thus imposed at the FE model base nodes, in the form of assigned acceleration time histories in the longitudinal $(x)$ and transversal $(z)$ directions.

The analysis and comparative discussion of the obtained results was then carried out by taking into account the average values of the maximum effects separately obtained, for each FE model, from each seismic record composing the set of accelerograms.

The (i) top drift of the full building assembly, as well as (ii) the maximum deformations and (iii) reaction forces achieved in the supporting brackets/devices and (iv) the occurrence of plastic hinges in the steel frame were first considered, at this stage of analysis.

A typical example of the obtained results is proposed in Fig. 11, in the form of top drift for the M0 building with rigid brackets and the MK1 configuration. As shown, the applied vibration control devices can markedly enhance the seismic performance of the reference structural system, with a strong decrease of maximum displacements and seismic effects in general. In particular, from Fig. 11 it is possible to perceive a reduction of maximum displacements for the MK1 control point up to 40\% the M0 displacements. This effect mostly depends on the beneficial contribution of the glazing curtain wall acting as distributed TMD system for the reference building. Beside the observed variations of fundamental period for the two examined configurations (see also Fig. 9(c)), together with a prevalent global vibration shape for both of them (i.e. Figs. 7(a) and 9(a)), these modifications as well as the input acceleration amplitudes (see also Fig. 10(b)) do not justify alone such magnitude of benefits on the observed seismic performance of the MK1 system, hence suggesting the potential of the examined solution.

As far as a certain flexibility is introduce at the level of façadeto-frame connection, however, an appropriate balance between expected structural benefits and performance of the devices themselves/ full 3D assembly should be first guaranteed, i.e. especially in terms of maximum deformations in the devices as well as in the IGU components.

Fig. 12, in this sense, presents a comparative summary of the main results derived from the full seismic investigation carried out as described above. In the Fig., the maximum top drift and the maximum deformation at the devices' level are proposed for the M0 model as well as for the MK1-to-MK5 configurations, while - for comparative purposes - the stiffer MK10 and MK50 configurations are disregarded. As far as the device stiffness increases, compared to the frame system (see MK10 and MK50 configurations of Table 2) the damping capacity of devices further increases. On the other hand, as numerically observed via dynamic simulations on the full 3D assembly, limited relative displacements only are attained in the connectors, with minimum damping contributions and overall benefits.

Each one of the dots collected in Fig. 12, in particular, was calculated through the seismic parametric study as the average value deriving from the maximum envelope value (in absolute terms) of deformations due to the assigned set of seismic records. 


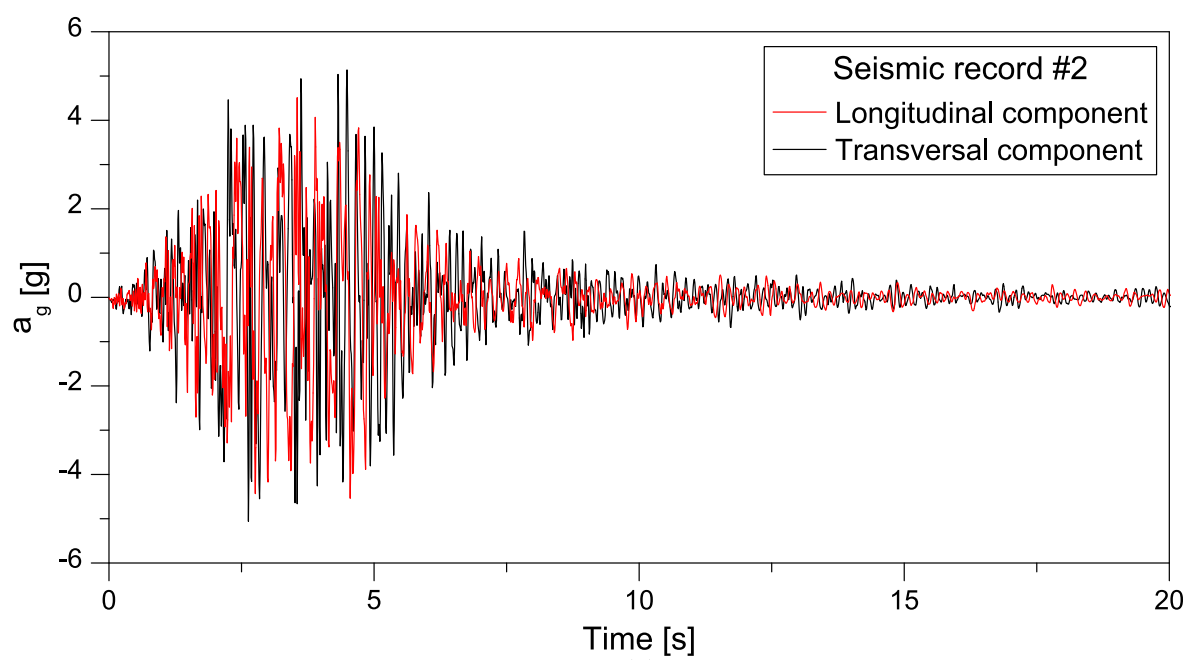

(a)

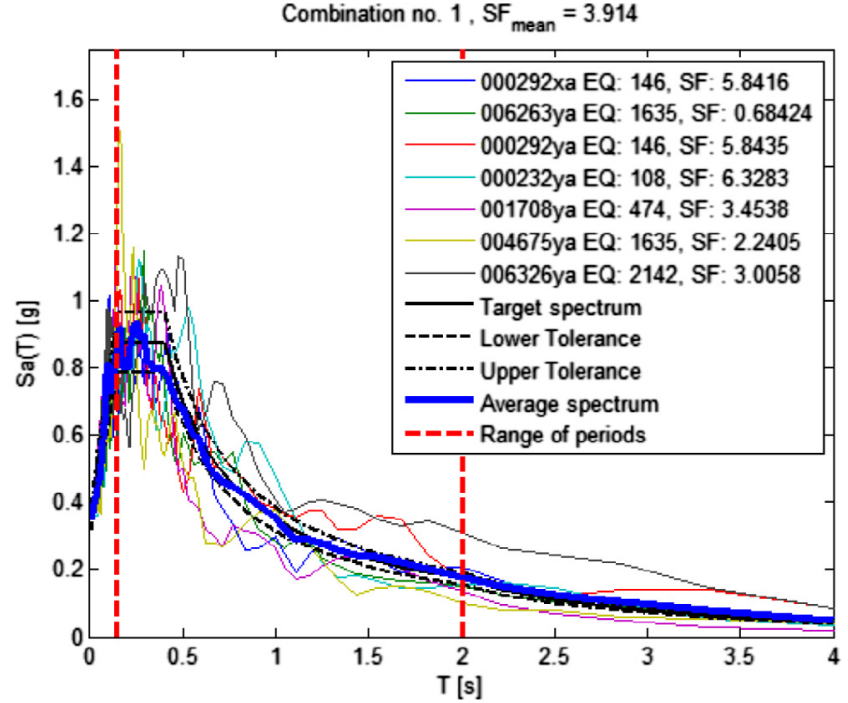

(b)

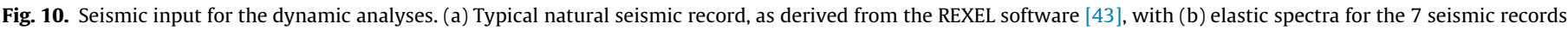
and comparison with the Eurocode 8 elastic spectrum.

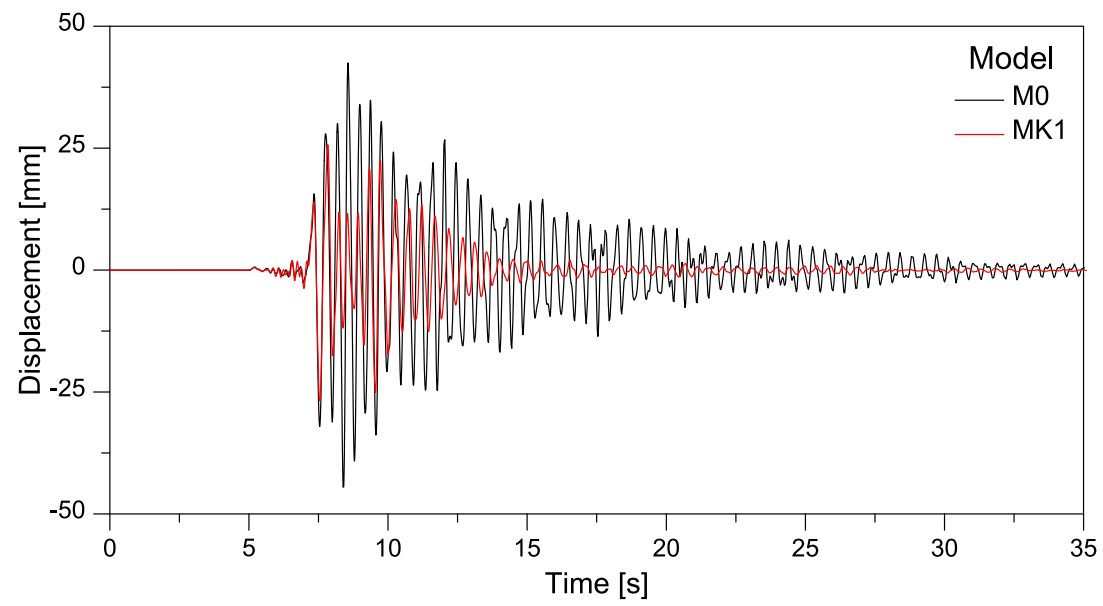

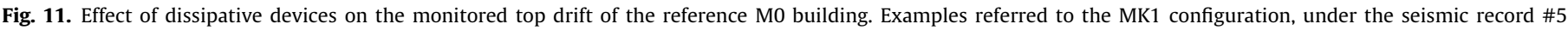
(ABAQUS). 


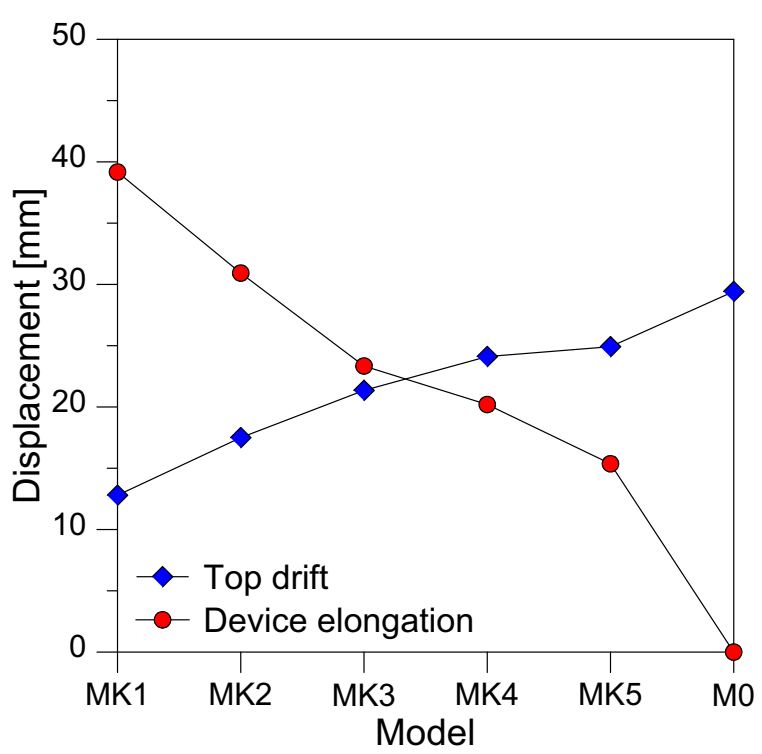

Fig. 12. Effect of vibration control devices on the monitored top drift of the reference building under the assigned set of 7 seismic records. In evidence, the corresponding relative deformations achieved in the devices themselves (ABAQUS).

As shown, despite the MK1 solution proved to reduce the top drift deformations of the building up to $\approx 60 \%$ the M0 value (see Figs. 11 and 12), it is clear that the effort required by the proposed MK1 passive devices would lead to excessive deformations for the dissipative layer, i.e. in the order of $\approx 40 \mathrm{~mm}$. For intermediate stiffness configurations (i.e. MK3 and MK4 cases), conversely, an interesting balance of effects can indeed observed, with a reduction of the M0 maximum top drift in the order of $\approx 20-30 \%$, in conjunction with maximum deformations in the devices themselves up to $\approx 20-25 \mathrm{~mm}$.

In terms of maximum stresses achieved in the steel frame members, the M0 building structure typically manifested the occurrence of plastic hinges at the beam ends, under the assigned set of seismic records. Fig. 13a presents an example of distribution of plastic hinges, for the transversal frame FT2 (see the labels provided in Fig. 4). In the case of the MK1 to MK4 FE models with vibration control devices, conversely, it is interesting to notice that no plastic hinges were noticed in the steel members, and an overall deformed shape agreeing with Fig. 13b was generally obtained for them. In the case of the MK5, MK10 and MK50 models, with rather stiff passive devices, a proportional increase of yielding and partial opening of plastic hinges having the same distribution of Fig. 13a was observed.

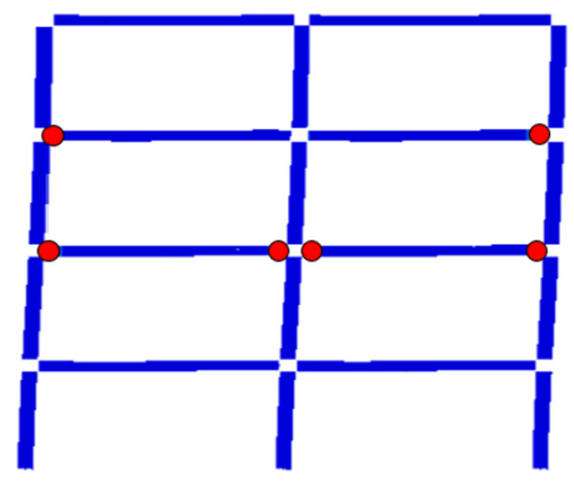

(a)
In this sense, for the reference case study, the optimal configurations in terms of global seismic performance of the investigated 3D assemblies were found to be associated to the MK3-MK4 models, being these models associated to rather appreciable decrease of the maximum top drift in the frame $(\approx 20 \%$ of the M0 building), limited deformations in the devices themselves (in the order of $\approx 20-30 \mathrm{~mm}$ ) and avoidance of plastic hinges occurrence in the steel frame.

\section{Effects of vibration control devices on the IGU dynamic performance}

Based on the comparative study partly discussed in Section 4, further FE simulations were than carried out on additional numerical models well representative of the nominal components and reciprocal interactions of a single IGU panel.

The FE study was developed in ABAQUS, in the form of eigenvalue, static and nonlinear dynamic simulations, so that additional recommendations and useful comparative results could be derived, i.e. in particular in terms of maximum deformations and principal stresses in the glass panels.

For this purpose, the typical FE model consisted of shell elements able to describe the physical geometry of each IGU unit, with careful consideration for the glass layers and the interposed cavity (see Fig. 14).

In accordance with the nominal thicknesses provided in Fig. 5, a multi-layer shell section representative of glass and interlayer foils was used for the laminated panel, while a monolithic section was assigned to the other glass ply. As in the case of the full 3D models, glass was mechanically described in the form of a linear elastic material $\left(E_{g}=70 \mathrm{GPa}, v_{g}=0.23, \rho_{g}=2490 \mathrm{~kg} / \mathrm{m}^{3}\right)$, but the occurrence of possible tensile damage was checked by direct comparison of the maximum achieved stresses with the corresponding characteristic resistance of glass. Assuming the monolithic and laminated panes composed of annealed float glass (with $45 \mathrm{MPa}$ the reference resistance [40]) and tempered glass respectively (120 MPa [40]), the first value was considered as the main influencing parameter for the discussion of the FE parametric results.

For the PVB film bonding together the laminated glass foils, a further idealized elasto-plastic material was taken into account, with $v_{\text {int }}=0.49, \rho_{\text {int }}=1100 \mathrm{~kg} / \mathrm{m}^{3}$ and $E_{\text {int }}=24 \mathrm{MPa}$, being this latter value associated to the PVB shear modulus under a short term load (3 s) and room temperature $\left(20^{\circ} \mathrm{C}\right.$ ), see [44].

A regular mesh pattern was used for both the composite and monolithic shell layers, with $50 \mathrm{~mm}$ the average size. The mechanical interaction between the external and internal panel - being the two glass panels divided by a cavity gap of $16 \mathrm{~mm}$ in thickness

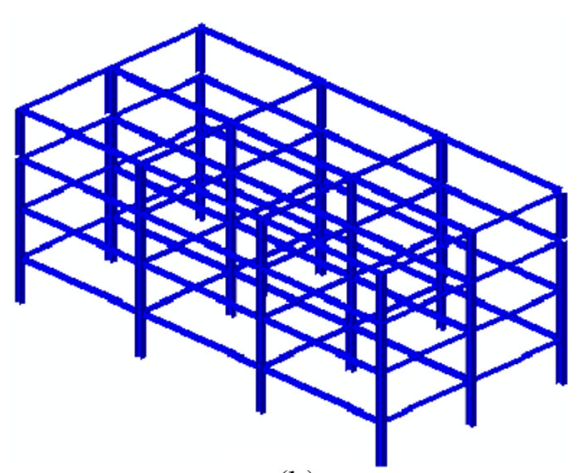

(b)

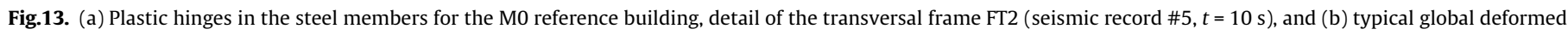
configuration for the MKn models (ABAQUS). 


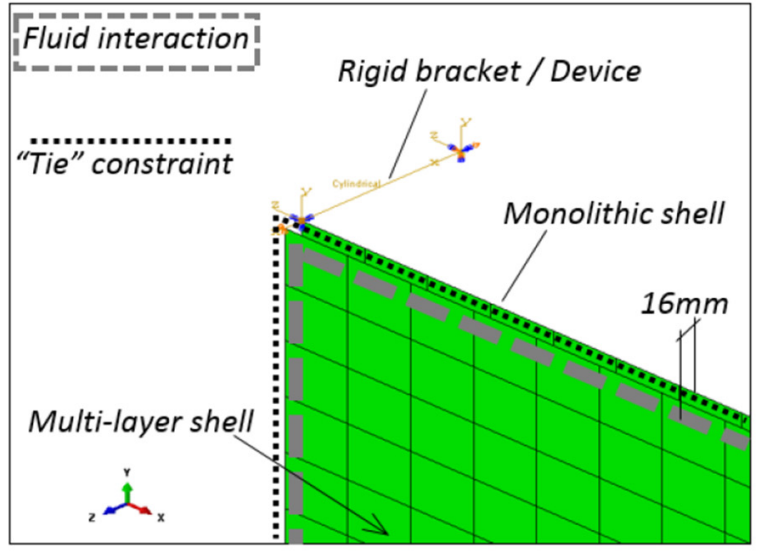

(a)

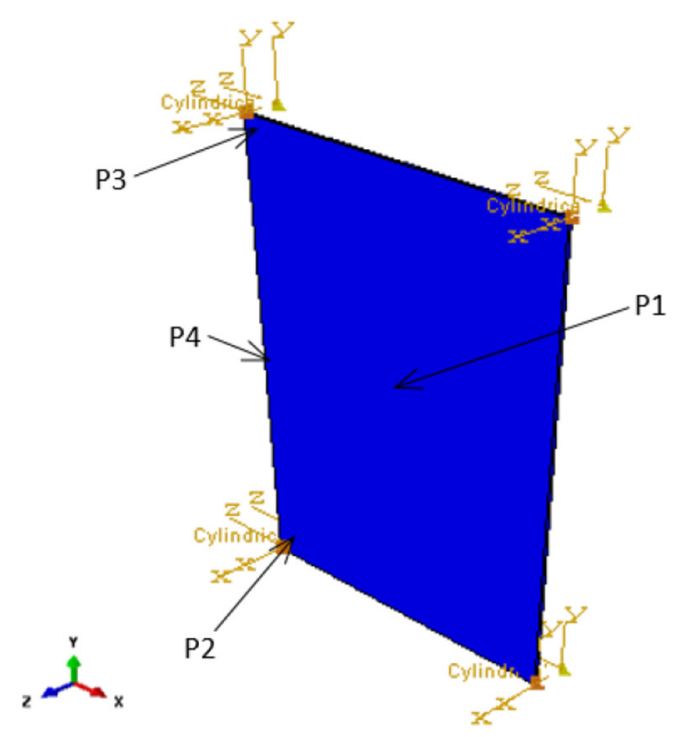

(b)

Fig. 14. (a) FE assembly of a single IGU panel, detail, and (b) reference control points (ABAQUS).

and filled with air - was then guaranteed by appropriate mechanical interactions available in the ABAQUS library [29]. Along the IGU's edges, a fully rigid "tie" constraint was first assigned to all the nodes belonging to the four edges of both the shell panels. This modelling assumption was chosen in order to mechanically reproduce - against the action of out-of-plane pressures, as in the current FE study - the presence of an almost rigid metal spacer and sealant joint along the four IGU's edges (see the detail provided in Fig. 5). The latter geometrical detail proved to have a key role on the collected FE results. Given a non-uniform variation over time of relative displacements imposed at the IGU connection points, as well as the boundary and supporting configuration, stress peaks were in fact observed also close to the connection points for the IGU pane in bending (see Section 5.1).

The appropriate transmission of loads from a glass panel to the other (i.e. load sharing effect), at the same time, was taken into account via a mechanical "fluid cavity interaction" available in ABQUS and able to describe - based on the equation of state of ideal gasses - the effects deriving from the presence of a given fluid (air, in this study) within the cavity. In doing so, for the air infill a pneumatic gas with ideal molecular weight $M_{\text {air }}=28.97 \mathrm{~kg} / \mathrm{kmol}$ was defined, with $p_{\text {air }}=1 \mathrm{~atm}$ the reference atmospheric pressure for the cavity. The effects on the initial volume of the cavity itself, e.g. deriving from possible temperature or altitude variations, were fully neglected.

In terms of vibration control devices - supposed to act at the interface between the IGU's corners and the structural background (i.e. the steel frame) - the connectors were mechanically described as in the case of the full 3D assemblies, and then rigidly fixed to ground (see Fig. 3, Section 3 and Fig. 14a). The so assembled FE models, for the M0 configurations as well as for the MKn selected cases of Table 2, were then investigated both under dynamic and static loads.

\subsection{Seismic analysis of a single IGU panel}

In terms of seismic performance, each one of the so assembled IGU models was subjected to the displacement time-history derived from Section 4.3.2, from the corresponding full 3D building assemblies, and investigated via nonlinear dynamic simulations.
For all the M0 and MKn configurations of Table 2, specifically, the IGU panel subjected to the maximum deformations under seismic events was first detected in each one of the corresponding full $3 \mathrm{D}$ models, so that the recorded displacements (i.e. the maximum deformations achieved at the bracket/control device level) could be used as input deformation for the IGU refined FE models. In doing so, given the maximum deformations achieved at the top of the building, relative displacement histories were calculated for the and bottom connection points of each IGU and the dynamic analysis was carried out in terms of relative imposed displacements only. On one side, this methodology was adopted so that maximum effects of a given seismic record could be emphasized, based on assigned facade module features and devices properties. At the same time, an intrinsic limit of the accounted FE approach is that the actual effects due to a combination of inertial forces deriving from seismic loads and relative movements at the module supports are not explicitly considered. Beside that, given the limited mass and stiffness contributions of a single facade unit compared to the full building assembly, the obtained FE results were considered reliable for the current stage of the research study.

The same approach was considered for all the seven seismic records composing the reference set (Fig. 10). The advantage of this solving procedure was given by the accurate estimation of stress and displacement effects due to an assigned design load, compared to the full 3D assemblies in which the mass contribution of the glazing curtain wall was only taken into account. The potential of a given $\mathrm{MK}_{i}$ control system was then quantified by taking into account the average maximum effects due to the assigned set of seismic records, as separately obtained from the corresponding FE simulations. In doing so, based on earlier FE outcomes for the full 3D system, the MK10 and MK50 configurations were disregarded.

The so obtained comparative results are proposed in Fig. 15, where the beneficial contribution of the examined dissipative devices is further emphasized. In terms of principal stress in glass, in particular (see Fig. 15a), the maximum peaks of stress were found to be located in the vicinity of the corners of each panel (i.e. control points P2 and P3), as well as at the panel centre (point P1). These maximum values of stress can be rationally justified by the imposed acceleration time histories, i.e. namely resulting in a partially non-symmetrical out-of-plane deformation of the IGUs, following the lateral deformation of the main steel frame at the 


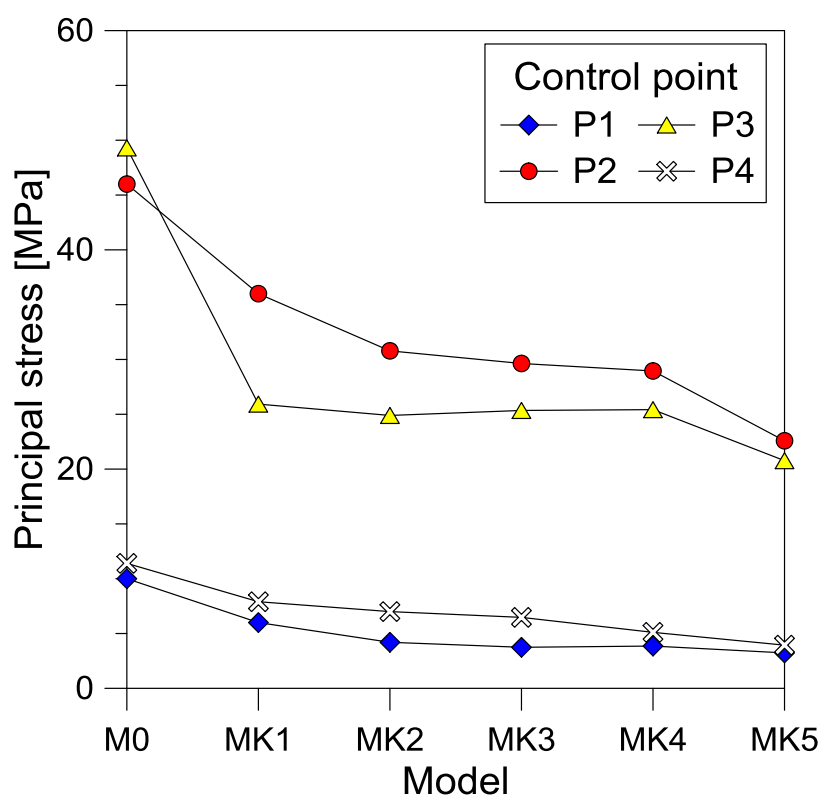

(a)
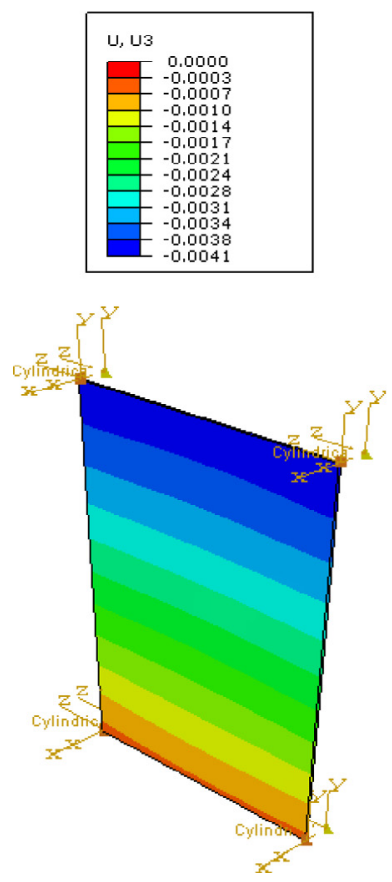

$t=0.5 \mathrm{~s}$
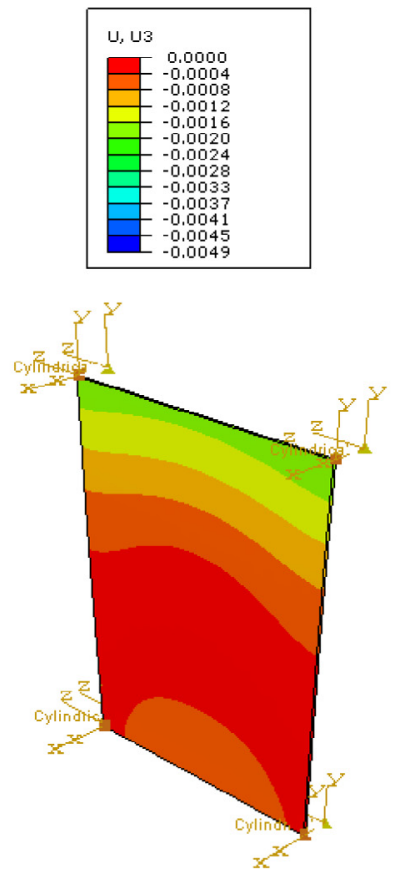

$t=1.7 \mathrm{~s}$

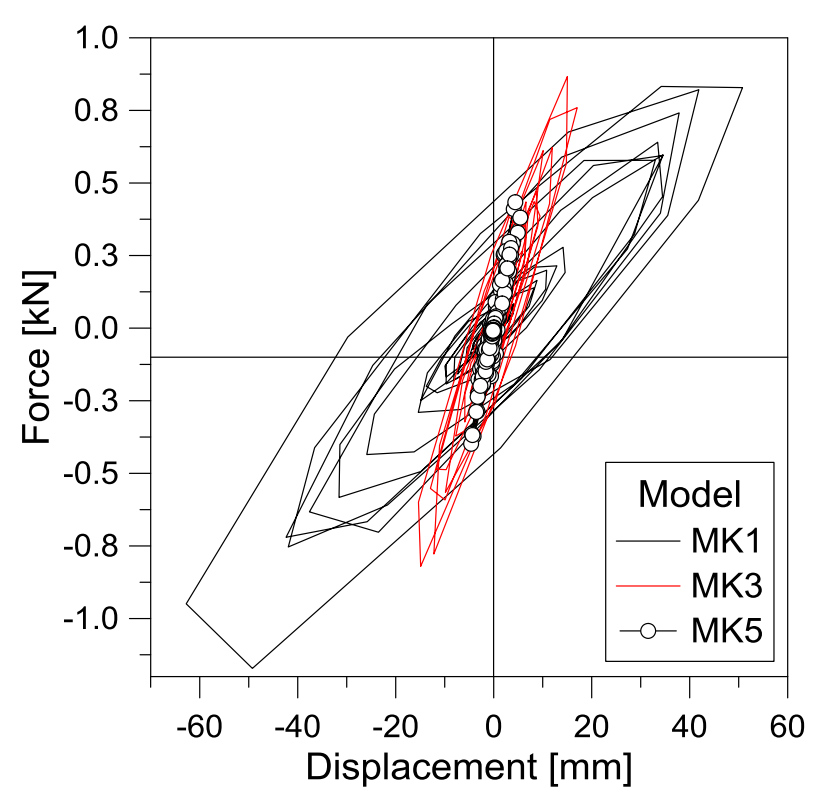

(b)
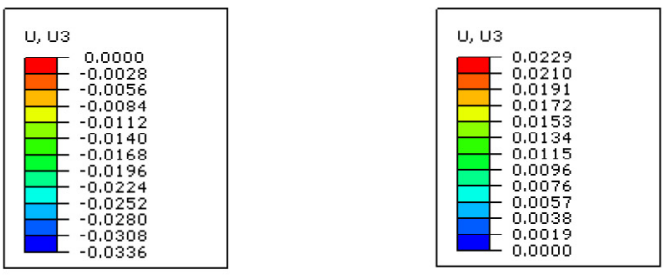

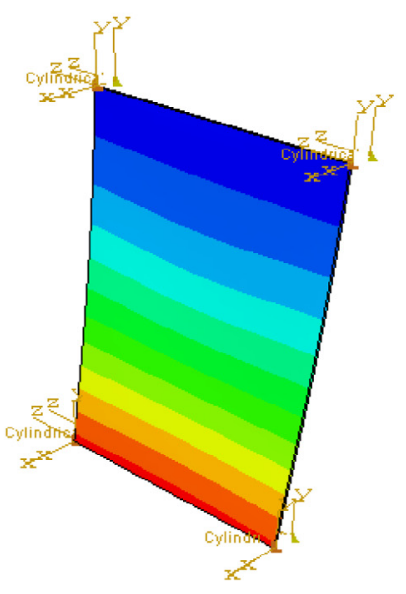

$t=2.6 \mathrm{~s}$

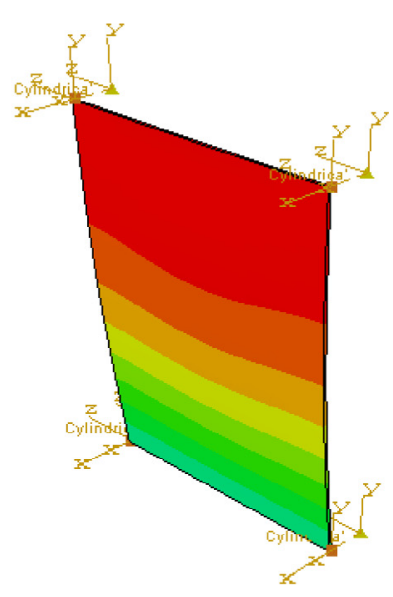

$t=3.3 \mathrm{~s}$

(c)

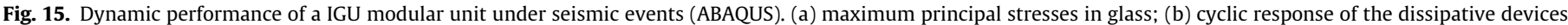

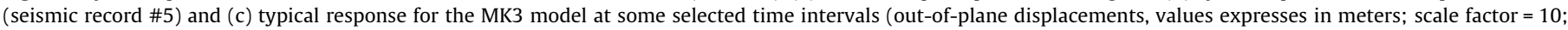
seismic record \#5).

level of inter-storey floors (see Fig. 15c). As far as a rigid linear constraint is considered to connect together the glass panes (i.e. being representative of the actual metal spacer), relative rotations are also prevented for the nodes belonging to the lateral edges of glass panes, hence resulting - for the assigned boundary and imposed displacement condition - in a sort of clamp restraint.

From Fig. 15 it is possible to notice, in particular, that as far as a certain flexibility and damping capacity is assigned to the devices object of investigation, the seismic effects on the full 3D assembly are mitigated (see Section 4), and consequently - due to the lower deformation demand, plus the active contribution of dissipative supports - the maximum stresses in glass are further controlled.

While for the M0 system a maximum stress of $\approx 50 \mathrm{MPa}$ was achieved at the control point P3, it can be seen that for the MK1 to MK5 solutions, this maximum value can be reduced up to $\approx 60 \%$ the original value (Fig. 15(a)). As a result, assuming the 
monolithic glass panes are composed of annealed float glass, with $45 \mathrm{MPa}$ the characteristic tensile resistance, the tensile failure could be prevented for all the MK1 to MK5 configurations.

Another implicit advantage deriving from the use of dissipative brackets is then represented by the maximum reaction forces the devices should resist and transfer to the supporting steel frame. While the maximum reaction force transmitted from the glass panels to the steel frame was found in the order of $\approx 2.8 \mathrm{kN}$ for the M0 model with fully rigid brackets, this reference value was strongly mitigated by the implemented vibration control systems, with values in the order of $\approx 0.9 \mathrm{kN}$ for the MK3 model (see Fig. 15(b) for a selection of MK1, MK3 and MK5 results), hence further emphasizing the efficiency of the proposed design concept.

From the same Fig. 15(b) it also possible to observe that as far as the assigned stiffness increases for the proposed devices, despite their expected damping capacity ideally increases (Table 2), limited amount of dissipated energy is achieved, due to reduced relative deformations.

As in the case of the dynamic analyses on the full 3D models, however, the maximum elongation of the devices resulted to be the major influencing parameter for their optimal design. According to Eq. (10), Table 2 and Fig. 15(b) it is in fact possible to notice that the MK1 solution would generally result in maximum deformations exceeding the recommended limit value for the rubber layer, while the feasibility of devices with mechanical properties agreeing with the MK3 configuration was further validated.

\section{Conclusions}

In this paper, the feasibility and potential of passive control systems consisting in glazing curtain walls with damping connectors has been numerically investigated via extended Finite-Element numerical investigations. Careful consideration has been paid for a reference case study, consisting in a 4-storey continuous steel frame subjected to seismic events.

The explored design concept directly derives from the original tuned-mass-damper (TMD) design philosophy, which has also been recently extended to double skin facades acting as passive vibration control systems for tall building under wind or seismic lateral loads.

As shown in the paper, for the reference case study, glazing curtain walls can often represent the critical component of buildings under exceptional loads or high-rise dynamic events in general.

The implementation of special mechanical connectors able to work as dissipative supports for the same glazing modular units proved, however, to represent an efficient tool for the mitigation of the maximum effects deriving from a seismic load, both in terms of global dynamic performance and local effects (i.e. at the level of the glazing components). Major benefits - in presence of properly designed devices - were in fact achieved in terms of reduction of (i) maximum top displacements for the steel frame, (ii) maximum tensile stresses, (iii) deformations in the glazing components, and (iv) avoidance of plastic hinges in the steel members, with moderate maximum deformations achieved at the level of the dissipative connectors.

It is thus expected, based on the current outcomes, that the explored design concept could be further investigated and optimized.

\section{References}

[1] Bedon C, Amadio C. Exploratory numerical analysis of two-way straight cablenet facades subjected to air blast loads. Eng Struct 2014;79:276-89.

[2] Amadio C. Bedon C. Viscoelastic spider connectors for the mitigation of cablesupported facades subjected to air blast loading. Eng Struct 2012;42:190-200.
[3] Amadio C, Bedon C. Elastoplastic dissipative devices for the mitigation of blast resisting cable-supported glazing facades. Eng Struct 2012;39:103-15.

[4] Amadio C, Bedon C. Blast analysis of laminated glass curtain walls equipped by viscoelastic dissipative devices. Buildings 2012;2(3):359-83.

[5] Bedon C, Amadio C. Passive control systems for the blast enhancement of glazing curtain walls under explosive loads. Open Civ Eng J 2017;11(suppl-1, M8):396-419.

[6] Nestovito G, Occhiuzzi A. Implementation of smart-passive dampers combined with double concave friction pendulum devices to retrofit an existing highway viaduct exploiting the seismic early warning information. Eng Struct 2016;120:58-74.

[7] Greco R, Marano GC. Multi-objective optimization of a dissipative connection for seismic protection of wall-frame structures. Soil Dyn Earthq Eng 2016;87:151-63.

[8] Oinam RM, Sahoo DR. Seismic rehabilitation of damaged reinforced concrete frames using combined metallic yielding passive devices. Struct Infrastruct Eng Maint Manage Life-Cycle Design Perform 2016. http://dx.doi.org/10.1080/ 15732479.2016.1190766. Published online.

[9] Fathi F, Bahar O. Hybrid coupled building control for similar adjacent buildings. KSCE J Civ Eng 2016. http://dx.doi.org/10.1007/s12205-016-0708x. Published online.

[10] Lee C-H, Kim J, Kim D-H, Ryu J, Yu YK. Numerical and experimental analysis of combined behavior of shear-type friction damper and non-uniform strip damper for multi-level seismic protection. Eng Struct 2016;114:75-92.

[11] Lievens K, Lombaert G, De Roek G, Van den Broeck O. Robust design of a TMD for the vibration serviceability of a footbridge. Eng Struct 2016;123:408-18.

[12] Wen Q, Hua X, Chen Z, Yang Y, Niu H. Control of human-induced vibrations of a curved cable-stayed bridge: design, implementation, and field validation. J Bridge Eng 2016. http://dx.doi.org/10.1061/(ASCE)BE.1943-5592.0000887. Published online.

[13] Pisal AY, Jangid RS. Vibration control of bridge subjected to multi-axle vehicle using multiple tuned mass friction dampers. Int J Adv Struct Eng 2016;8 (2):213-27.

[14] Wang J, Lin C, Chen B. Vibration suppression for high-speed railway bridges using tuned mass dampers. Int J Solids Struct 2003;40:465-91.

[15] Poh'sie GH, Chisari C, Rinaldin G, Amadio C, Fragiacomo M. Optimal design of tuned mass dampers for a multi-storey cross laminated timber building against seismic loads. Earthq Eng Struct Dyn 2016. http://dx.doi.org/10.1002/ eqe.2736. Published online.

[16] Gaspar CMR, Santos da Silva JG, Costa-Neves LF. Multimode vibration control of building steel-concrete composite floors submitted to human rhythmic activities. Comput Struct 2016;165:107-22. http://dx.doi.org/10.1016/ i.compstruc.2015.12.010.

[17] Song G, Zhang P, Li L, Singla M, Patil D, Li H, et al. Vibration control of a pipeline structure using pounding tuned mass damper. J Eng Mech 2016. http://dx.doi. org/10.1061/(ASCE)EM.1943-7889.0001078. Published online.

[18] Zhao X, Wang L, Zheng Y. Combined tuned damper-based wind-induced vibration control for super tall buildings. J Tongji Univ 2016:44(4):550-8.

[19] Tong X, Zhao X, Zhao Z. Passive structural vibration control of a monopole wind turbine tower. In: Proceedings of the IEEE conference on decision and control; 2016. p. 1352-7.

[20] Den Hartog J. Mechanical vibrations. New York: Mc-Graw Hill; 1956.

[21] Lee C-L, Chen Y-T, Chung L-L, Wang Y-P. Optimal design theories and applications of tuned mass dampers. Eng Struct 2006;28:43-53.

[22] Warburton G. Optimum absorber parameters for minimizing vibration response. Earthq Eng Struct Dyn 1981;9:251-62.

[23] Hoang N, Fujino Y, Warnitchai P. Optimal tuned mass damper for seismic applications and practical design formulas. Eng Struct 2008;30(3):707-15.

[24] Mohebbi M, Joghataie A. Designing optimal tuned mass dampers for nonlinear frames by distributed genetic algorithms. Struct Design Tall Spec Build 2012:21(1):57-76.

[25] Moon KS. Integrated damping system for tall buildings: tuned mass damper/double skin façade damping interaction system. Struct Design Tall Spec Build 2016;25(5):232-44

[26] Moon KS. Vertically distributed multiple tuned mass dampers in tall buildings: performance analysis and preliminary design. Struct Design Tall Spec Build 2010;19:347-66.

[27] Moon KS. Tall building motion control using double skin facades. ASCE J Archit Eng 2009;15(3):84-90

[28] Palmeri A, Barone G, Khetawat A. Passive control of building structures using double-skin facades as vibration absorbers. In: Proceedings of the fifteenth international conference on civil, structural and environmental engineering computing. Stirlingshire (UK): Civil-Comp Press; 2015. http://dx.doi.org/10. 4203/ccp.108.94 [paper 94].

[29] Systèmes Dassault. ABAQUS v. 6.12. Providence (RI); 2013.

[30] Fujita S, Morikawa S, Suizu Y, Fujita T, Teramoto T, Kitamura H, et al. Development of high damping rubber damper for vibration attenuation of high-rise buildings. In: Proceedings of 10th WCEE - world conference on earthquake engineering 1992:4(7):2097-101.

[31] Nakao M, Yamaguchi N, Furuta T. Development of a passive damper device with high damping rubber for wooden houses. In: Proceedings of the 8th international conference on structural dynamics - EURODYN 2011, Leuven, Belgium; 2011 [paper code: 116680].

[32] Teramoto T, Kitamura H, Ozaki H, Furuya O, Morikawa S, Suzuki S. Practical application of high-damping rubber dampers to a slender building. In: 
Proceedings of 11th WCEE - world conference on earthquake engineering; 1996 [paper no. 1801].

[33] Park SW. Analytical modeling of viscoelastic dampers for structural and vibration control. Int J Solids Struct 2000;38:8065-92.

[34] EN 1998-1-1. Eurocode 8 - Design of structures for earthquake resistance Part 1: General rules, seismic actions and rules for buildings. Brussels (Belgium): CEN; 2004.

[35] Chopra AK. Dynamics of structures-theory and applications to earthquake engineering. 4th ed. Prentice Hall; 2011.

[36] EN 1991-1-1. Eurocode 1 - Actions on structures - Part 1-1: General Actions. Brussels (Belgium): CEN; 2004.

[37] EN 1993-1-1. Eurocode 3 - Design of steel structures - Part 1-1: General rules and rules for buildings. Brussels (Belgium): CEN; 2004.

[38] Xiaoming C, Jin D, Yungui L. Mass proportional damping in nonlinear timehistory analysis. In: Proceedings of 3rd international conference on material, mechanical and manufacturing engineering, IC3ME2015, June 27-28, 2015, Guangzhou, China; 2015
[39] Alipour A, Zareian F. Study Rayleigh damping in structures - uncertainties and treatments. In: Proceedings of 14th world conference on earthquake engineering, October 12-127, 2008, Beijing, China; 2008.

[40] EN 572-2:2004. Glass in buildings - basic soda lime silicate glass products. Brussels (Belgium): CEN; 2004.

[41] Fuller KNG, Gough J, Pond TJ, Ahmadi HR. High damping natural rubber seismic isolators. J Struct Control 1997;4(2):19-40.

[42] Malek KA, Basir KB. Design and characteristics of high damping natural rubber bearings for base isolation. Trans Built Environ 2001:57:155-67.

[43] Iervolino I, Galasso C, Cosenza E. REXEL: computer aided record selection for code-based seismic structural analysis. Bull Earthq Eng 2010;8(2):339-62. http://dx.doi.org/10.1007/s10518-009-9146-1.

[44] Van Duser A, Jagota A, Bennison S. Analysis of glass/polyvinyl butyral laminates subjected to uniform pressure. J Eng Mech 1999;125(4):435-8. 